\title{
Percepções e reflexões de estudantes sobre indisciplina em aulas de educação física
}

\author{
Student perceptions and reflections on indiscipline in physical education classes
}

Percepciones y reflexiones de los estudiantes sobre la indisciplina en las clases de educación física

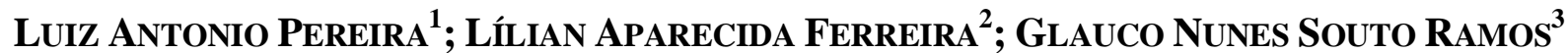 \\ Universidade Federal de São Carlos, UFSCAR, São Carlos-SP, Brasil \\ Universidade Estadul Paulista “Júlio de Mesquita Filho”, UNESP, Bauru-SP, Brasil
}

\begin{abstract}
RESUMO
Os objetivos da pesquisa foram identificar situações de indisciplina em uma turma do $5^{\circ}$ ano do ensino fundamental e analisar percepções e reflexões dos estudantes sobre a temática a partir de ações didáticopedagógicas. A investigação caracterizou-se pela pesquisa-ação e os instrumentos de coleta de dados foram: diários de aula e rodas de conversa. Foram identificadas situações de bagunça, conversas paralelas, agressões verbais e xingamentos. Notou-se certa resistência por parte de alguns estudantes para perceber como problematizar a indisciplina nas aulas. Alunos e professor, conjuntamente, construíram regras de convivência e diversos jogos de cooperação que buscaram despertar respeito pelo outro, compromisso e responsabilidade. A promoção de uma proposta de enfrentamento da indisciplina não deve vir acompanhada da ilusão de que os conteúdos em si vão resolver os problemas. É importante que o professor tenha claro que os resultados demandam tempo, exigindo paciência e comprometimento.
\end{abstract}

Palavras-chave: Educação Física Escolar. Indisciplina. Jogos de Cooperação.

\begin{abstract}
The objectives of the research were to identify situations of indiscipline in a class of the 5th year of elementary school and to analyze students' perceptions and reflections on the theme from didactic-pedagogical actions. The investigation was characterized by action research and the data collection instruments were: class diaries and conversation circles. Messy situations, side conversations, verbal aggressions and name-calling were identified. Some resistance was noted by some students to understand how to problematize indiscipline in class. Students and teacher, together, built rules of coexistence and several games of cooperation that sought to awaken respect for others, commitment and responsibility. The promotion of a proposal to confront indiscipline must not be accompanied by the illusion that the content itself will solve the problems. It is important that the teacher is clear that the results take time, requiring patience and commitment.
\end{abstract}

Keywords: School Physical Education. Indiscipline. Cooperation Games.

\section{RESUMEN}

Los objetivos de la investigación fueron identificar situaciones de indisciplina en una clase de $5^{\circ}$ año de primaria y analizar las percepciones y reflexiones de los estudiantes sobre el tema a partir de acciones didácticopedagógicas. La investigación se caracterizó por la investigación acción y los instrumentos de recolección de datos fueron: diarios de clase y círculos de conversación. Se identificaron situaciones desordenadas, conversaciones secundarias, agresiones verbales y apodos. Algunos estudiantes notaron cierta resistencia a entender cómo problematizar la indisciplina en clase. Alumnos y docente, juntos, construyeron reglas de convivencia y varios juegos de cooperación que buscaban despertar el respeto por los demás, el compromiso y la responsabilidad. La promoción de una propuesta para enfrentar la indisciplina no debe ir acompañada de la ilusión de que el propio contenido resolverá los problemas. Es importante que el profesor tenga claro que los resultados llevan tiempo, requiriendo paciencia y compromiso.

Palabras clave: Educación Física Escolar. Indisciplina. Juegos de Cooperación.

\footnotetext{
${ }^{1}$ Mestre em Educação Física (ProEF/UFSCar). Professor da rede pública municipal e estadual da cidade de Matão-SP. E-mail: lumessas@ @otmail.com. ORCID: http://orcid.org/0000-0003-3445-883X.

2 Professora do Departamento de Educação Física e do Programa de Pós-Graduação em Docência para a Educação Básica da UNESP de Bauru. E-mail: lilian.ferreira@unesp.br. ORCID: http://orcid.org/0000-00018517-4795.

${ }^{3}$ Professor Associado do Departamento de Educação Física e Motricidade Humana da UFSCar e do Programa de Mestrado Profissional em Educação Física em Rede Nacional (ProEF/UFSCar). E-mail: glauco@ufscar.br. ORCID: http://orcid.org/0000-0003-2644-2838.
} 


\section{INTRODUÇÃOO}

A indisciplina é vista como um grande problema educacional, afetando a dinâmica e o desenvolvimento dos processos educativos e relacionais dentro do contexto das aulas e da escola. A Educação Física não escapa ilesa a este problema. Situações cotidianas de indisciplina são comuns e apresentam-se como um entrave ao desenrolar das aulas, prejudicando o aprendizado dos alunos e dificultando os avanços e aprofundamentos das temáticas propostas pelo professor.

As soluções a essa problemática são difíceis, pois envolvem várias questões que precisam ser discutidas e analisadas em profundidade. A Educação Física, como componente curricular da escola, pode contribuir com reflexões e ações que buscam minimizar estes enfrentamentos.

Neste sentido, o presente artigo teve como objetivos identificar situações de indisciplina em uma turma do $5^{\circ}$ ano do ensino fundamental e analisar percepções e reflexões dos estudantes sobre a temática a partir de ações didático-pedagógicas em aulas de Educação Física.

Esta investigação está vinculada à dissertação de mestrado intitulada "Os jogos sociomotrizes de cooperação e a construção de valores acerca da indisciplina discente" (PEREIRA, 2020) desenvolvida junto ao Programa de Mestrado Profissional em Educação Física Escolar em Rede Nacional - ProEF, que agrega dozes instituições superiores de ensino, dentre elas a Universidade Federal de São Carlos (UFSCar). Tal programa busca o desenvolvimento profissional de professores de Educação Física que atuam nas redes públicas de ensino.

\section{INDISCIPLINA, COTIDIANO ESCOLAR E EDUCAÇÃO FÍSICA}

A indisciplina não é um problema de hoje, ela acompanha a história da educação e o percurso trilhado por esta temática demonstra que ela vem acompanhando a sociedade ao longo dos tempos (OLIVEIRA, 2001). Até mesmo seu conceito apresenta uma complexidade que precisa ser considerada (GARCIA, 1999), pois a percepção quanto ao que é indisciplina pode variar conforme o tempo e o momento histórico. Mas, este fator ainda que variável não exclui a necessidade de alguma definição. Elas são importantes porque contribuem para que possamos ter uma visão mais esclarecedora e uma melhor reflexão sobre o tema.

Para Estrela (1994, p. 17) "[...] o termo indisciplina surge geralmente associado com o de disciplina e tende a ser definido pela sua negação ou privação ou desordem proveniente da quebra de regras estabelecidas".

La Taille (2012) citado por Paula, Paixão e Oliveira (2015, p. 461), define a indisciplina "[...] como toda ação moral executada pelo sujeito e que está em desacordo com as leis impostas ou construídas coletivamente, tendo consciência ou não deste processo de elaboração".

A indisciplina, geralmente, se associa à quebra das regras estabelecidas e que, por este motivo, leva a um ambiente perturbador que pode provocar tensões e conflitos nas relações pedagógicas e relacionais.

Dentro do ambiente escolar, a indisciplina pode estar associada a vários fatores. Oliveira (2005) aponta alguns determinantes que podem estar relacionados a este problema e os separa em duas categorias: a) os fatores psicossociais: a família, a mídia, a diversidade entre os alunos, problemas de distúrbios e a carência afetiva e, b) os fatores pedagógicos: a imposição ou falta de regras, a busca do "clima ideal" em sala de 
aula, os cursos de formação de professores, a proposta pedagógica, o sistema educacional e a escola.

Com base nos elementos apresentados por Oliveira (2005), podemos dizer que a indisciplina, geralmente, não vem associada somente a um tipo específico de problema que se relaciona a ela, mas, pode estar associada a mais de um fator, o que leva a comunidade escolar e em especial os professores e a direção escolar a ter um olhar cuidadoso para as várias dimensões por ela apresentada.

Nas questões vinculadas ao problema da indisciplina, precisamos discutir e avaliar o seu oposto: a disciplina. Afinal, os debates sobre a questão de como estabelecer o controle sobre os alunos de modo a torná-los mais respeitosos e obedientes durante o processo educativo tem se acalorado nos últimos tempos, principalmente, devido ao afloramento na atualidade das escolas militarizadas.

Segundo Guimarães e Lamos (2018, p. 66) esse tipo de escola constitui-se em uma nova forma de gestão, uma mistura de privatização com militarismo e, que vem ganhando espaço em diversos estados brasileiros. Como exemplo, temos o estado de Goiás que, em 2001, criou o Colégio da Polícia Militar de Goiás (CPMG) através da Lei Estadual $\mathrm{n}^{\circ}$ 14.050, transformando Escolas Estaduais em instituições de ensino geridas pela Polícia Militar do Estado de Goiás (PMGO). Para Guimarães e Lamos (2018) a implantação deste tipo de gestão no estado de Goiás, tem como pressuposto diminuir a violência e melhorar o desempenho dos alunos em um ambiente seguro para alunos, professores e funcionários.

Este modelo vem se apresentando como uma solução para o problema da violência escolar e, pelos resultados conseguidos, tem chamado a atenção de parte da sociedade civil. Mas, apesar dos resultados, os mesmos autores apontam as contradições desse sistema. Como exemplo, temos: a não participação na gestão democrática, pois, elas são regidas por uma ordem hierárquica, em que os militares tomam as posições de comando no sistema, com os professores em uma escala abaixo deles; cobrança de taxas, que foram alvo de inúmeras críticas por parte da comunidade escolar, mesmo sendo estas "voluntárias"; o modelo de ingresso dos alunos, sendo cinquenta por cento destinadas aos filhos de policiais militares e outros cinquenta por cento destinados a sorteio público aberto à comunidade estudantil, mediante inscrição no processo seletivo.

Como pode ser notado, este modelo apesar de apresentar melhoras nos índices de aprovação e diminuição da violência não foi concebido para ser universalizado. Mesmo estando em bairros com altos índices de violência, estas escolas não abrangem todos os estudantes que estão inseridos nestas comunidades.

Em relação ao Governo Federal, foi criado o Decreto $n^{\circ} 10.004 / 19$ que estabelece o Programa Nacional das Escolas Cívico-Militares (PECIM). Uma iniciativa do Ministério da Educação com a parceria do Ministério da Defesa, cujo objetivo é a implantação de 216 escolas neste modelo até o ano de 2023, sendo que a adesão de estados e municípios deve ocorrer de maneira voluntária ao programa (BRASIL, 2019). Segundo o MEC (BRASIL, 2019) cinquenta e quatro milhões serão destinados em investimentos ao programa no ano de 2020, ao qual será lançado um projeto-piloto com cinquenta e quatro escolas participantes selecionadas, com cada uma delas recebendo um milhão de reais em verbas, que serão gastos com melhorias na infraestrutura e pagamento aos militares participantes do programa.

Destaca-se que muitas das críticas feitas sobre as escolas de Goiás cabem ao programa federal, uma vez que muitas dessas escolas têm em comum, por exemplo: um maior aporte financeiro por parte do governo federal, estadual e municipal, uma seletiva na escolha dos alunos e cobranças de taxas "voluntárias". Segundo Reis et al. (2019, p. 234) "[...] entende-se que a subordinação de profissionais da educação e estudantes a 
militares consiste em um ataque aos princípios democráticos do nosso país e descaracteriza a escola pública como espaço de emancipação humana".

Para Guimarães e Lamos (2018, p. 77) este tipo de escola com disciplina e hierarquia militares "[...] formam cidadãos adestrados e conformados com os trabalhos simples, somada a uma consciência acrítica que servirá a uma ordem voltada para os interesses da classe dominante detentora dos meios de produção com o agravante de sequer perceber isso".

A defesa destes modelos considerados "disciplinadores" nunca deixou de estar presente no debate educacional. Ela teve, durante um longo tempo, fortes críticas, sendo alguns desses críticos: Foucault, Bourdieu, Freire entre outros.

Segundo Furlan e Peri (2009), para Foucault, o poder disciplinador na escola tem como objetivo tornar os corpos dóceis, obedientes e úteis. Para que isso ocorra são necessários recursos educacionais nos quais as crianças e os jovens são preparados para se tornarem obedientes, produtivos e aptos para o trabalho.

Para Santos (2014, p. 493): “[...] muitas tecnologias do poder disciplinador voltadas para a docilização dos corpos, controlando os discursos e produzindo sujeitos, são constitutivas do espaço escolar, ontem e hoje".

Acreditamos que muitas práticas disciplinadoras promovidas pelos professores e pela escola, ainda se caracterizam por um certo autoritarismo, buscando condicionar os alunos a uma obediência restrita às ordens impostas de cima para baixo, não promovendo o diálogo e a reflexão sobre a importância de cumprir as regras, como construção coletiva.

Em contrapartida a esta proposta, devemos destacar a posição de disciplina que é defendida por Paulo Freire e que se baseia na autonomia e na liberdade do educando. Nesta proposta é fundamental a ação do professor, agindo sempre com autoridade e não com autoritarismo. Para Freire (1996, p. 23) “[...] como educador, devo estar constantemente advertido a esse respeito que implica igualmente o que devo ter por mim mesmo". Segundo Lourenço Filho, Lima e Guimarães (2013, p. 68)

[...] para o educador, a disciplina é fundamental para o crescimento do aluno, exigindo que sempre haja uma autoridade paterna e docente, pois é esta autoridade que permite ao aluno perceber que a disciplina não é somente uma necessidade individual, mas também social.

Tanto a autoridade do professor quanto da escola, devem ser exercidas no sentido de levar os alunos a compreenderem a importância da disciplina em suas vidas e na coletividade. Para que isso ocorra são necessários espaços de diálogo e reflexão, onde todos podem vivenciar o direito de respeitar e ser respeitado.

Em relação à Educação Física, Darido, González e Ginciene (2018) indicam que a indisciplina não é apenas um problema da Educação Física, mas uma manifestação que se vincula às peculiaridades da rotina deste componente curricular. As características das dinâmicas das aulas, bem como, seu espaço e lógica interna das atividades propostas, são apontados por alguns autores como potencializadores de indisciplina dentro do contexto das aulas deste componente curricular (DARIDO; GONZÁLES; GINCIENE, 2018; FONTOURA, 2013; MARQUES; RAMOS; FERREIRA, 2020; SANT'ANA, 2012).

Para Oliveira (2001) citado por Fontoura (2013) as características especiais das aulas de Educação Física, em virtude de diferentes contextos (ginásio, pavilhões, espaços ao ar livre) e por terem um envolvimento menos estruturado e mais aberto, são mais propícias a problemas de indisciplina. 
Segundo Sant'Ana (2012) as aulas de Educação Física apresentam uma dinâmica diferente na escola e, por envolver atividades ligadas aos conteúdos da cultura corporal e às práticas corporais, acabam contribuindo para a maximização dos conflitos e das questões ligadas às atitudes e aos valores.

Em estudo realizado por Marques, Ramos e Ferreira (2020) foram identificados conflitos em formas de xingamentos, discussões desrespeitosas e agressões físicas em jogos esportivos de futsal e handebol manifestados por estudantes de turmas de Educação Física do $6^{\circ}$ ano do ensino fundamental de uma escola da rede pública estadual de São Paulo. Entre outros aspectos, os autores indicam que os conflitos podem assumir significativo espaço para mobilização de reflexões entre professores e alunos, favorecendo uma melhora na relação entre eles nas aulas e fora delas (MARQUES; RAMOS; FERREIRA, 2020).

Ao buscarem o envolvimento dos alunos através da cooperação, alguns estudos indicam uma melhora no comportamento disciplinar dos alunos mediante a prática dos jogos cooperativos (BRANDL NETO; WALDOW, 2010; CANDATEN, 2013; UHLIG; SANTOS, 2008; WEILLER; TEIXEIRA, 2012;), sendo relacionados, principalmente, os aspectos ligados ao companheirismo, à empatia e às relações de comportamento individual e em grupo.

Diante das circunstâncias apresentadas, entendemos que os professores de Educação Física precisam buscar dentro do contexto da cultura corporal de movimento, possibilidades pedagógicas e relacionais que visem o enfrentamento da indisciplina. Nesse sentido, a utilização de vivências de atividades voltadas para a percepção e reflexão dos alunos pode ser importante ferramenta a ser promovida.

\section{TRAJETÓRIA METODOLÓGICA}

A abordagem investigativa de natureza qualitativa se orientou pela pesquisa-ação. Tripp (2005, p. 447) define a pesquisa-ação, como "[...] uma forma de investigaçãoação que se utiliza de técnicas de pesquisa consagradas para informar a ação que se decide tomar para melhorar a prática".

Participaram da pesquisa 25 alunos de uma mesma turma do $5^{\circ}$ ano do ensino fundamental de uma escola pública municipal do interior de São Paulo. Esta turma integrou o estudo pois era considerada bastante indisciplinada pela gestão e por vários professores da escola em questão. Cumpre sinalizar que o professor de Educação Física também foi o pesquisador deste estudo, exercendo simultaneamente estes dois papeis.

Os instrumentos de coleta de dados utilizados foram: diários de aula (ZABALZA, 2004) e rodas de conversa (MOURA; LIMA, 2014; SILVEIRA; BRITO, 2017).

Segundo Zabalza (2004, p. 14) os diários de aula constituem "documentos pessoais" ou "narrações autobibliográficas", de orientação basicamente qualitativa, que foram adquirindo um grande relevo na pesquisa educativa nos últimos anos. Destacamos dois aspectos cujos quais os diários de aula podem auxiliar: a) recolher informações significativas sobre o processo de ensino e de aprendizagem que está sendo realizado e as particularidades circunstâncias em que fazemos e, b) analisar os dados e refletir sobre os fatos, momentos, problemas e assuntos.

Em relação às rodas de conversa, temos que "[...] são consideradas um dispositivo para promover a aprendizagem. Elas promovem a democratização das comunicações na sala de aula, em busca de conhecimento. São momentos em que se priorizam a fala e a escuta de todos os participantes dispostos em roda em um mesmo ambiente" 
(SILVEIRA; BRITO, 2017) e, desta forma, podem colaborar positivamente no processo da pesquisa.

Para a realização das aulas foram elaboradas estratégias que envolveram um conjunto de ações visando a percepção e reflexão entre os alunos e professorpesquisador sobre a indisciplina.

Destaca-se que, do ponto de vista da ética de realização de pesquisas com seres humanos, os alunos aceitaram participar ao assinarem o Termo de Autorização Livre e Esclarecido (TALE), bem como, foi obtida a autorização dos responsáveis dos alunos através do Termo de Consentimento Livre e Esclarecido (TCLE). Houve também a autorização da direção da escola para a realização da pesquisa. Tal investigação foi aprovada pelo Comitê de Ética da Universidade Federal de São Carlos, através do parecer $\mathrm{n}^{\circ} 3.451 .642$.

Para a análise dos dados coletados foi utilizado o recurso da interpretação e confronto das informações (MINAYO, 1996), buscando uma interpretação que mais se aproxime da realidade. De acordo com a autora, esse tipo de análise envolve três passos: 1. Ordenação dos dados; consiste no mapeamento de todos os dados, nas descrições dos diários de aula e das anotações feitas a partir das rodas de conversa, na leitura e releitura do material e organização dos dados. 2. Classificação dos dados: através de repetidas leituras dos dados, constitui-se a configuração da análise. Gomes (1996) ao descrever essa fase afirma que: "Através de uma leitura exaustiva e repetida dos textos, estabelecemos interrogações para identificarmos o que surge de relevante ('estruturas relevantes dos atores sociais')” (p. 78). 3. Análise final: Articulação dos dados com o referencial teórico da pesquisa, procurando responder às questões da pesquisa de acordo com os objetivos, "[...] promovendo relações entre o concreto e o abstrato, o geral e o particular, a teoria e a prática" (GOMES, 1996, p. 79).

\section{ANÁlise dos ReSultados}

As manifestações de indisciplina podem prejudicar o desenrolar das aulas, pois tendem a comprometer o tempo para iniciá-las e desenvolvê-las. Segundo Silva (2010, p. 01) "[...] os comportamentos de indisciplina podem, dependendo da frequência que ocorrem em uma sala de aula, perturbar significativamente a relação pedagógica, afetando as aprendizagens e a socialização dos alunos".

Neste sentido, ao longo das anotações feitas nos diários de aula foram identificadas as seguintes manifestações de indisciplina na turma analisada: resistência quanto à proposta do professor, bagunça, conversas paralelas, agressões verbais e xingamentos.

Estas identificações possibilitaram foco e organização, tanto por parte do professor de Educação Física quanto dos alunos, para a construção de ações que auxiliassem este coletivo na reflexão sobre a indisciplina.

A constituição de um espaço para a proposição e diálogo sobre regras e valores se deu por meio de assembleias de construção do pacto pedagógico. Estas, envolviam atividades reflexivas e práticas que ocorreriam para mobilizar a reflexão dos principais problemas de indisciplina da sala e, depois disso, estabelecer coletivamente um conjunto de regras para o seu cumprimento.

No início, para os alunos, os principais desafios em torno da indisciplina da turma eram a falta de educação e a falta de respeito, aspectos estes mais claramente visualizados nos diários de aula do professor-pesquisador. 
Comecei a escrever na cartolina o checklist, com aquilo que os alunos consideravam como principais problemas de indisciplina da sala. Fazia as anotações com as questões que eram mais faladas pelos alunos e perguntava se eles concordavam ou não com o que eu iria colocar, iniciei o checklist com: falta de educação e falta de respeito, ao qual todos concordaram. Perguntei o que mais eles acreditavam que precisava ser colocado, muitos começaram a falar a palavra bullying (Diário de Aula 02).

Perguntei para eles o que poderia ser colocado como indisciplina, uma aluna respondeu que [...] seria: "Faltar com respeito! " Outros começaram a entrar no meio dizendo: "Brigar", "Bater", "Xingar", "Não respeitar o professor" (Diário de Aula 04).

Após um diálogo sobre todo esse processo, alunos e professor de Educação Física, compuseram juntos um conjunto de ações que foram por eles denominadas de situações de indisciplina:

1- Falta de respeito;

2- Falta de educação;

3- Bullying;

4- Conversas e brincadeiras paralelas;

5- Homofobia;

6- Falta de atenção.

Definidas tais situações, após acordo de todos, foi iniciada a construção das regras que teriam que ser observadas e seguidas pelo coletivo da turma. Afinal, como propõe Caetano (2014, p. 790) "[...] para a formação do desenvolvimento moral e dos valores é preciso que o grupo construa conjuntamente suas regras, e que estas façam sentido para eles".

Outro fragmento de um diário de aula produzido pelo professor-pesquisador explicita como foi este processo:

Continuaram dando opiniões para escrever no cartaz; muitas coisas foram sendo faladas e coloquei nesta lista três regras: ser amigável, levantar a mão para falar e obedecer aos professores. Perguntei se eles estavam de acordo com o que eu havia escrito, mas muitos continuavam fazendo muito barulho quando eu tentava falar... comecei a perguntar se eles concordavam, pedi para que levantassem as mãos para que pudéssemos verificar se eles concordavam com o que estava sendo escrito no cartaz. Acabamos ficando com cinco regras:

1- Levantar a mão quando for falar;

2- Ser educado com todos;

3- Ser amigável;

4- Obedecer ao professor;

5- E não gritar (Diário de Aula 02).

Essa dinâmica de participação coletiva nos processos decisórios foi denominada de assembleias do pacto pedagógico, pois permitiram colocar em discussão vários aspectos relacionados à dimensão atitudinal. Levando os alunos a refletirem sobre os comportamentos da turma.

Para Brasil (1998), a dimensão atitudinal busca promover nos alunos a construção de valores, normas e atitudes que permitem a boa convivência e harmonia entre as pessoas dentro do ambiente escolar, ela precisa ser colocada em pauta de uma maneira clara, haja vista que esta temática em muitas situações fica restrita dentro daquilo que é chamado de currículo oculto. 
Dar ênfase a esta temática, trazer à tona esta discussão e promover uma ação conjunta entre todos os membros da escola é fundamental para que a construção de valores possa tomar uma dimensão significativa, na qual todos tenham como premissa o respeito às diferenças e a valorização da sua pessoalidade.

Além do diálogo aberto, a elaboração das regras de convivência e a dinâmica das assembleias do pacto pedagógico, outro recurso para mobilizar os alunos a perceber e refletir sobre a indisciplina foram os jogos de cooperação. Isso se deu porque estes jogos possuem, em sua estrutura e dinâmica, a interação de colaboração entre os participantes voltada para atingir um objetivo comum, promovendo a cooperação e o trabalho em equipe (PEREIRA, 2020). Estudos demonstram que o trabalho com jogos desta natureza pode contribuir para a melhora dos aspectos relacionados à indisciplina (BRANDL NETO; WALDOW, 2010; CANDATEN, 20013; UHLIG; SANTOS, 2008; WEILLER; TEIXEIRA, 2012).

Quando o professor estabeleceu uma interlocução com os alunos relacionada aos eventuais desdobramentos que os jogos de cooperação poderiam trazer para a questão da indisciplina, alguns deles se manifestaram.

Fiz uma pergunta: se eles acreditavam que aqueles tipos de jogos, jogos de cooperação, poderiam ajudar a melhorar a indisciplina? Um menino respondeu que sim.

Perguntei para outro menino. Ele respondeu que sim, porque eram jogos que todos tinham que participar.

Participar?

Sim, um ajuda o outro.

Vocês concordam? (Diário de Aula 10).

Outro fator importante, foi estimular os alunos a compreenderem a importância do trabalho mútuo e da ação cooperativa na realização das atividades:

Tentei fazer que falassem mais um pouco. Perguntei a uma aluna se ela sabia o que era cooperação, então me respondeu: "que era ajudar o outro". Perguntei também se era preciso cooperação nas atividades que fizemos, ela falou: "Sim, porque tem que todo mundo ajudar" (Diário de Aula 07).

Apesar da dinâmica e estrutura desses jogos serem essencialmente colaborativas, as relações conflituosas também podem aparecer em seus contextos, na medida em que, como aponta Marques (2019, p. 27) "[...] os conflitos ocorrem nas relações entre pessoas e/ou grupos, em toda a sociedade, incluindo a educação escolar e as aulas de educação física”. Isso pode ser identificado na situação na qual os alunos estavam fazendo um jogo de cooperação que envolvia passar a bola para o outro com o auxílio de um lençol.

Na primeira tentativa a bola foi jogada para fora e nas tentativas seguintes os alunos estavam tendo dificuldades para passar a bola de um lençol para o outro, começaram então a discutir uns com os outros, cada um querendo falar como deveria ser feito e alguns culpando os amigos que não conseguiam passar a bola (Diário de Aula 07).

Apesar deste conflito, igualmente é possível assinalar a potencialidade educativa que a experiência, se mediada pelo professor, pode proporcionar aos alunos: a busca coletiva para a resolução de um problema que o jogo está apresentando. 
Tentei retornar a conversa para o assunto dos jogos cooperativos, perguntando se eles achavam importante trabalhar coletivamente. A maioria respondeu que sim. Continuei perguntando se eles achavam importante esse tipo de atividade em que um tem que ajudar ao outro para atingir um objetivo; uma aluna me respondeu que sim, que era importante trabalhar em equipe. Perguntei: "Por quê?". Ela respondeu que era porque "um podia ajudar o outro" (Diário de Aula 05).

A introdução de jogos estritamente cooperativos pode, em princípio, proporcionar um certo estranhamento, haja vista que as aulas de Educação Física costumam ter preponderância da interação competitiva entre os alunos nas atividades desenvolvidas. A vivência de uma outra estrutura advinda da interação cooperativa possibilita a experimentação de outras relações sociais que podem contribuir para novas reflexões acerca da própria sociedade em que vivemos, bem como, favorecer a incorporação de atitudes que deem mais relevo às ações coletivas, pensada em prol de um bem comum.

$\mathrm{O}$ professor pode trabalhar os aspectos comportamentais relacionados aos jogos envolvendo cooperação, mostrando as possiblidades e conduzindo os alunos a refletirem sobre sua postura e comportamento nas aulas, reforçando aspectos relacionados à responsabilidade coletiva, ao companheirismo e à solidariedade.

\section{CONSIDERAÇÕES FINAIS}

Quanto à indisciplina nas aulas de Educação Física da turma analisada, observamos algumas dificuldades, principalmente relacionadas às conversas paralelas, discussões e ofensas pessoais entre os alunos durante as aulas. Para enfrentar este desafio, buscamos promover ações, em parceria com os alunos, voltadas a favorecer a percepção e mobilizar a reflexão sobre a indisciplina.

Essas ações propiciaram aos alunos e ao professor-pesquisador a oportunidade, por meio do diálogo, de refletirem sobre suas atitudes e mobilizarem outras formas de olhar e agir diante da indisciplina. Nesse sentido, podemos sinalizar que as vivências resultantes das atividades realizadas inauguraram outras relações entre os participantes.

Ainda assim, vale destacar que a promoção de uma proposta de enfrentamento em relação à indisciplina não deve vir acompanhada da ilusão de que os conteúdos propostos em si vão resolver os problemas da indisciplina, já que este se revela com um elemento multifatorial e relacionado a uma problemática socialmente mais ampla. Por esta via, é fundamental considerar que isso envolve um trabalho que carece de continuidade e, portanto, de tempo, na medida em que não se trata de moldar comportamentos, mas de refletir sobre eles em prol de mudanças efetivas nas relações entre as pessoas.

\section{REFERÊNCIAS}

BRANDL NETO, I.; WALDOW, J. N. C. Jogos cooperativos em uma $5^{\circ}$ série do ensino fundamental. Cadernos de Educação Física, v. 9, n. 16, p. 85-96, 1. sem. 2010.

BRASIL. Decreto-lei ${ }^{\circ}$ 10.004, de 05 de setembro de 2019. Institui o Programa Nacional das Escolas Cívico-Militares. Diário Oficial da União: Seção 1, Brasília, DF, n. 1, p. 1-7, 05 set. 2019.

BRASIL. Parâmetros Curriculares Nacionais. Brasília, DF: MEC/SEF, 1998.

CAETANO, A. O jogo nas aulas de Educação Física e suas implicações no desenvolvimento moral. Pensar a Prática, Goiânia, v. 17, n. 3, p. 783-799, jul./set. 2014. 
CANDATEN, A. P. Educação física escolar: jogos cooperativos como conteúdo para $4^{\circ}$ série do ensino fundamental. 2013. 40f. Monografia (Trabalho de Conclusão do curso de Educação Física) Universidade Regional do Noroeste do Estado do Rio Grande do Sul (Unijuí), Ijuí, 2013.

DARIDO, S. C.; GONZÁLES, F. J.; GINCIENE, G. O afastamento e a indisciplina dos alunos nas aulas de educação física escolar. Mestrado Profissional em Educação Física em Rede Nacional - ProEF - Disciplina: Problemáticas da Educação Física, 2018.

ESTRELA, M. T. Relação pedagógica, disciplina e indisciplina na aula. 2. ed. Porto: Porto Editora, 1994.

FONTOURA, M. F. Indisciplina e jogos de regras na Educação Física Escolar. 2013. 80 f. Dissertação (Mestrado em Educação) - Universidade Tuiuti do Paraná, Curitiba, 2013.

FREIRE, P. Pedagogia da autonomia: saberes necessários à prática educativa. 25. ed. São Paulo: Paz e Terra, 1996.

FURLAN, M. B.; PERI, M. Michel Foucault: corpos dóceis e disciplinados nas instituições escolares. In: CONGRESSO NACIONAL DE EDUCAÇÃO - EDUCERE, 9., 2009, Curitiba. Anais [...]. Curitiba, 2009. p. 2390-2403.

GARCIA, J. Indisciplina na escola: uma reflexão sobre a dimensão preventiva. Revista Paranaense de Desenvolvimento, Curitiba, n. 95, p. 101-108, jan./abr. 1999.

GOMES, R. A análise de dados em pesquisa qualitativa. In: MINAYO, M. C. S. (org.). Pesquisa social: teoria, método e criatividade. 8. ed. Petrópolis: Vozes, 1996. p. 67-80.

GUIMARÃES, P. C. P.; LAMOS, R. A. C. Militarização da rede estadual de Goiás: a nova onda conservadora. Revista pedagógica. v. 20, n. 43, p. 66-80, jan./abr., 2018.

LOURENÇO FILHO, A.; LIMA, B. C. M. T.; GUIMARÃES, G. H. E. Um diálogo entre as concepções de disciplina de Kant, Dewey e Freire. Impulso, Piracicaba, v. 23, n. 56, p. 61-72, 2013.

MARQUES, R. G. V. Conflitos nas aulas de educação física escolar: reflexões assentadas na pesquisaação e na Praxiologia Motriz. 2019. Dissertação (Mestrado em Docência para a Educação Básica) Faculdade de Ciências, Universidade Estadual Paulista "Júlio de Mesquita Filho", Bauru, 2019.

MARQUES, R. G. V.; RAMOS, G. N. S; FERREIRA, L. A. Conflitos em jogos de futsal e de handebol: reflexões praxiológicas. Conexões, Campinas, v. 18, p. e020018, 2020.

MINAYO, M. C. S. Pesquisa social: teoria, método e criatividade. 8. ed. Petrópolis: Vozes, 1996.

MOURA, A. B. F.; LIMA, M. G. S. B. A reinvenção da roda: um instrumento metodológico possível. Interfaces na Educação, Parnaíba, v. 5, n. 15, p. 4-35, 2014.

OLIVEIRA, M. I. Indisciplina escolar: determinações, consequências e ações. Brasília: Liber Livro Editora, 2005.

OLIVEIRA, M. T. G. M. A indisciplina em aulas de educação física: estudo das crenças e procedimentos dos professores relativamente aos comportamentos de indisciplina dos alunos nas aulas de educação física do $2^{\circ}$ e $3^{\circ}$ ciclos do ensino básico. 2001. Tese (Doutorado em Ciências do Desporto) Faculdade de Ciências do Desporto e Educação Física, Universidade do Porto, Porto, 2001.

PAULA, E. S; PAIXÃO, J. A.; OLIVEIRA, E. C. Suspensão das aulas de educação física como forma de punição: a perspectiva discente. Pensar a prática, Goiânia, v. 18, n. 2, p. 461-471, abr./jun. 2015.

PEREIRA, L. A. Os jogos sociomotrizes de cooperação e a construção de valores acerca da indisciplina discente. 2020. 165 f. Dissertação (Mestrado Profissional em Educação Física em Rede 
Nacional - ProEF) - Centro de Ciências Biológicas e da Saúde, Universidade Federal de São Carlos, São Carlos, 2020.

REIS, L. C. R.; ALVES, M. F.; SANTOS, E. J. F.; SILVA, F. L.; FERREIRA, N. S. R. Militarização de escolas públicas e o governo Bolsonaro. Tecnia, v. 4, n. 2, p. 227-235, 2019.

SANT’ANNA, A. S. S. A indisciplina na Educação Física Escolar. 2012. 149f. Dissertação (Mestrado em Educação Física) - Centro de Desportos, Universidade Federal de Santa Catarina, Florianópolis, 2012.

SANTOS, A. A. T. Discurso, memória e corpos dóceis: a (in)disciplina sobre o olhar dos professores. Palimpsesto, v. 13, n. 19, p. 476-494, 2014.

SILVA, L. C. Os professores e a problemática da indisciplina na sala de aula. In: SEMINÁRIO NACIONAL: CURRÍCULO EM MOVIMENTO. PERSPECTIVAS ATUAIS, 1., 2010, Belo Horizonte. Anais [...]. Belo Horizonte, 2010. p. 1-15.

SILVEIRA, T. A.; BRITO, R. G. A dinâmica das rodas de conversa em aulas de ciência no ensino fundamental. In: CONGRESSO INTERNACIONAL SOBRE INVESTIGACÍON EM LA DIDÁCTICA DE LAS CIENCIAS, 10., 2017, Sevilla. Anais [...]. Sevilla, 2017. p. 253-258.

TRIPP, D. Pesquisa-ação: uma introdução metodológica. Educação e Pesquisa, São Paulo, v. 31, n.3, p. 443-466, set./dez. 2005.

UHLIG, J. M.; SANTOS, S. L. C. Vencendo a indisciplina por meio dos jogos cooperativos. Paraná, 2008. Disponível em: http://www.diaadiaeducacao.pr.gov.br/portals/pde/arquivos/1798-8.pdf. Acesso em: 23 set. 2019.

WEILER, G. M. A.; TEIXEIRA, R. T. S. A contribuição da educação física na mediação da indisciplina e dos conflitos escolares. Paraná, 2012. Disponível em: http://www.diaadiaeducacao.pr.gov.br/portals/cadernospde/pdebusca/producoes_pde/2012/2012_uem_edf is_pdp_gleides_maria_angeli_weiler.pdf. Acesso em: 23 set. 2019.

ZABALZA, M. A. Diários de aula: um instrumento de pesquisa e desenvolvimento profissional. Porto Alegre: Artmed, 2004.

Recebido em: 18 dez. 2020.

Aprovado em: 10 abr. 2021. 